\title{
Dia do Orgulho Pagão no Brasil: obstáculos, frutos e diálogo
}

\author{
Pagan Pride Day in Brazil: Obstacles, fruits and dialogue
}

Karina Oliveira Bezerra ${ }^{1}$

\section{Resumo}

O dia do orgulho Pagão é uma iniciativa de um projeto criado nos Estados Unidos, com o nome: PaganPride Project ${ }^{\circledR}$. Foi realizado pela primeira em 19 de setembro de 1998. Houve 18 celebrações no primeiro ano, 17 nos Estados Unidos e uma no Canadá. Em 2001, ocorreram os primeiros eventos na Europa e no Brasil. Os principais objetivos da organização são o avanço das espiritualidades baseadas no Paganismo e a eliminação do preconceito, assim como da discriminação com base em crenças religiosas. A missão do PaganPride Project ${ }^{\circledR}$ é promover o orgulho da identidade Pagã através da educação, do ativismo, da solidariedade e da comunidade. O artigo visa demonstrar brevemente a trajetória desse evento no Brasil, realizado em todas as regiões do país, expandindo-se e arrefecendo em várias cidades. Verificar quais são os obstáculos e frutos relatados por alguns coordenadores locais e analisar como o projeto contribui para o diálogo religioso no Brasil. Realizamos pesquisa documental, entrevistas com coordenadores locais de regiões distintas, pesquisa intervenção, e análise de conteúdo.

Palavras-chave: Diálogo. Pluralismo Religioso, Neopaganismo.

\section{Abstract}

Pagan Pride Project is an initiative of a project created in the United States under the name: Pagan Pride Project $\AA$. It was held for the first time on September 19, 1998. There were 18 celebrations in the first year, 17 in the United States and one in Canada. In 2001, the first events took place in Europe and Brazil. The main objectives of the organization are the advancement of Paganism-based spirituality and the elimination of prejudice, as well as discrimination based on religious beliefs. The mission of the Pagan Pride

\footnotetext{
${ }^{1}$ Historiadora e mestra em Ciências da Religião, pela UNICAP. Bolsista capes de doutorado.
} 
Religare, ISSN: 19826605, v.15, n.2, dezembro de 2018, p.652-669.

Project ${ }^{\circledR}$ is to promote the pride of pagan identity through education, activism, solidarity and community. The article aims to show briefly the trajectory of this event in Brazil, carried out in all regions of the country, expanding and cooling in several cities. Check what are the obstacles and fruits reported by some local coordinators and analyze how the project contributes to religious dialogue in Brazil. We conduct documentary research, interviews with local coordinators from different regions, research intervention, and content analysis.

Keywords: Dialogue. Religious Pluralism, Neopaganism.

\section{Introdução}

As origens do termo Pagão são um pouco disputadas. Mas a maioria das autoridades derivam sua origem de pagus, uma área rural na antiga Roma, e paganus, o habitante do campo. Em seu livro Pagans and Christians, Robin Lane Fox diz que "A palavra apareceu pela primeira vez nas inscrições cristãs no início do século IV e permaneceu coloquial, nunca entrando nas traduções latinas da Bíblia. No uso diário, quer dizer um civil ou um rústico". (FOX, apud CLIFTON, 2006, p.77). Chas Clifton explica que esse civil era o "não alistado através do batismo como soldados do cristo". E também acrescenta que, apesar de os Pagãos contemporâneos associarem o termo à vida não urbana, e assim com as formas de conexão com Gaia, como uma religião da natureza, talvez o termo deva mais a atitude da militância cristã de "você é conosco ou contra nós". Michael Strmiska (2005, p.06) enfatiza que o termo só veio ter conotação religiosa com a utilização pejorativa, utilizada pelos cristãos.

No século XIX, o Romantismo promoveu uma valorização do termo pagão e trouxe imagens positivas das religiões Pagãs da Europa. Este é um dos motivos, segundo Michael Strmiska (2005, p.07), do resgate de um termo pejorativo, ao invés de uma nova designação livre de conotações negativas. A segunda razão é que, para o novo adepto, que, na maioria dos casos, era 
Religare, ISSN: 19826605, v.15, n.2, dezembro de 2018, p.652-669.

cristão, o termo Pagão resume em uma única palavra a quebra definitiva com o cristianismo. Muitos dos créditos da popularização do termo Pagão, mas, sobretudo, Neopagão, deve-se ao folheto publicado em 1970, intitulado: "Uma Velha Religião para uma Nova Era" da famosa revista Green Egg. Atualmente, no Cambridge Academic Content Dictionary (2018), existem duas definições para pagão, sendo ambas com conotações religiosas e apreciativas: “pertencente ou relacionado com uma religião que adora muitos deuses, especialmente uma que existisse antes das principais religiões do mundo." E "pertencente ou relacionado com uma religião moderna que inclui crenças e atividades que não são de nenhuma das principais religiões do mundo, por exemplo, a adoração da natureza." No que concerne à ortografia da palavra pagão, seguiremos os passos de Chas Clifton (2006), e utilizaremos Pagão com maiúsculo, para definir os adeptos da religião do Paganismo, modernos e antigos; e pagão com minúsculo, de forma genérica.

Assim, Neopaganismo é um movimento religioso contemporâneo, centrado no culto dos deuses antigos, sendo a natureza sacralizada e cultuada em ritos sazonais, com adaptação para a vida na sociedade moderna. Buscase inspiração e/ou reconstrução das antigas religiões pré-cristãs europeias, e para ganhar legitimidade e não sofrer preconceito, alguns adeptos idealizaram comemorar o “Dia do Orgulho Pagão (DOP)”.

O DOP é uma iniciativa de um projeto criado nos Estados Unidos, com o nome: Pagan Pride Project®. Foi realizado pela primeira vez em 19 de setembro de 1998. Houve 18 celebrações no primeiro ano, 17 nos Estados Unidos e uma no Canadá. Em 2001, ocorreram os primeiros eventos na Europa e no Brasil. Os principais objetivos da organização são o avanço das espiritualidades baseadas no Paganismo e a eliminação do preconceito, assim como da discriminação com base em crenças religiosas. A missão do Pagan Pride Project@ é promover o orgulho da identidade Pagã através da educação, do ativismo, da solidariedade e da comunidade. 
Religare, ISSN: 19826605, v.15, n.2, dezembro de 2018, p.652-669.

O artigo visa demonstrar brevemente a trajetória desse evento no Brasil, realizado em todas as regiões do país, expandindo-se e arrefecendo em várias cidades. Verificar quais são os obstáculos e frutos relatados por alguns coordenadores locais e analisar como o projeto contribui para o diálogo interreligioso no Brasil. Realizamos pesquisa documental, entrevistas com coordenadores locais de regiões distintas, pesquisa intervenção, e análise de conteúdo.

A pesquisa documental foi realizada na internet, em 2016. No entanto, obtivemos pouquíssimo material, pois os responsáveis pelas cidades onde o evento não é mais realizado apagaram as páginas com os conteúdos. Mas conseguimos contato via facebook com a maioria dos ex-coordenadores, esclarecendo dúvidas sobre o início e fim das atividades. Para isso utilizamos apenas perguntas informais.

Segundo Bogdan e Biklen (2010, p.51), “uma entrevista é utilizada para recolher dados descritivos na linguagem do próprio sujeito, permitindo ao investigador desenvolver intuitivamente uma ideia sobre a maneira como os sujeitos interpretam aspetos do mundo." É nesse sentido que, para obtermos as informações necessárias sobre o evento e o Projeto, e a questão dos frutos, obstáculos e diálogo, que realizamos entrevistas semiestruturadas, via Facebook, com 04 coordenadores locais atuantes, e com 01 ex-coordenador local, que também é o ex-coordenador nacional. Coincidentemente, os 04 escolhidos continuam no projeto, mas a seleção foi feita privilegiando regiões distintas do Brasil, no intuito de ter uma representatividade nacional. Devido a algumas problemáticas no DOP de Brasília, que representaria o CentroOeste, resolvemos colocar 02 cidades do Nordeste e reservar, para outro momento, a análise daquela região juntamente com as cidades que ficaram de fora.

A pesquisa intervenção foi feita na cidade do Recife, visto que eu sou a coordenadora local do evento há cinco anos, logo, sujeito implicado. 
Religare, ISSN: 19826605, v.15, n.2, dezembro de 2018, p.652-669.

A pesquisa intervenção tem "caráter desarticulador das práticas e dos discursos instituídos, inclusive os produzidos como científicos, substituindose a fórmula 'conhecer para transformar' por 'transformar para conhecer'”' (COIMBRA, apud, ROCHA, 2003). O sujeito implicado

é o sujeito que interroga, que é ao mesmo tempo o que produz o fenômeno sob análise e, mais ainda, é o que interroga o sentido do fenômeno partindo do lugar de quem dá sentido ao mesmo, e neste processo cria a própria significação de si e do fenômeno. Ou mais, ao saber sobre isso mexe no seu próprio agir, imediatamente e de maneira implicada. (MERHY, 2007)

Para exame dos dados, utilizamos a análise de conteúdo, verificando o que é explícito no texto para obtenção de indicadores que permitam fazer inferências. Entende-se por análise de conteúdo um conjunto de técnicas de análise das comunicações visando obter por procedimentos sistemáticos e objetivos de descrição do conteúdo das mensagens indicadores (quantitativos ou não) que permitam a inferência de conhecimentos relativos às condições de produção/receção (variáveis inferidas) destas mensagens. (BARDIN, 2009, p. 44)

\section{Surgimento e desenvolvimento}

As primeiras cidades a realizarem o DOP no Brasil foram São Paulo e Brasília, no ano já citado de 2001. Porto Alegre começou em 2004, Recife, Rio de Janeiro e Botucatu em 2012, Palmas em 2013, Manaus, Santana do Livramento, Belo Horizonte e Foz do Iguaçu em 2014, e Barra de São João em 2015. Além dessas 12 cidades, outras 02 cidades já realizaram o evento, são elas: Curitiba e Fortaleza.

2013 foi um ano de destaque para o evento no Brasil, pois, foi quando o país ganhou oficialmente uma coordenação nacional, representada pelo coordenador local de Porto Alegre, então intitulado Lugus Dagda Brigante,

subcoordenador regional para o Pagan Pride Project® Inc. América Central e do Sul - Brasil. Em entrevista Lugus informa que 
Religare, ISSN: 19826605, v.15, n.2, dezembro de 2018, p.652-669.

Nunca existiu uma Coordenação Nacional para o Brasil, antes de 2012. Nesse sentido, fui o primeiro Coordenador Nacional do Projeto em nosso país. Houve, por um pouco período de tempo (2001 a 2004) uma parceria da Abrawicca com o PaganPrideProjetc ${ }^{\circledR}$, a mantendo informalmente como responsável por alguns dos eventos (com exceção de Porto Alegre), mas a instituição de uma Coordenação Nacional nunca foi firmada antes de 2012, posto que os coordenadores locais foram abandonando suas cidades sem dar qualquer tipo de retorno ou satisfação ao $\mathrm{PPP}$. A função de Coordenador Regional Adjunto para América Latina Regional Brasil, foi criada pelo PPP, tendo em vista o aumento de cidades que aderiram ao Projeto entre 2007 e 2011 e foi entregue ao titular da Coordenação do DOP - Porto Alegre, por ser conhecido como único evento do PaganPride Project ${ }^{\circledR}$ mantido em caráter oficial (com o reconhecimento e filiação plena ao Projeto) de toda a América Latina e Europa, mantido de forma ininterrupta por tantos anos. (BRIGANTE, 2016)

O trecho em itálico foi destacado, pois, depois de fazer as entrevistas e análises, essa informação não encaixava na história. Então, no dia 22 de janeiro de 2017, retornei contato pelo Facebook com Lugus, informando-o da incoerência da informação. Pois nenhuma cidade aderiu ao projeto nesse intervalo de tempo. Dito isso, ele respondeu:

Realmente eu devo estar confundido as datas. Infelizmente ter coordenado o DOP no Brasil foi muito triste para mim e minha mente procurou apagar esse período da minha vida. Na verdade, a maioria dessas coordenações surgiram porque havia uma coordenação nacional. Talvez eu não tenha dito exatamente o período do aumento de cidades, exatamente porque foi após a instalação da coordenação nacional, e não gostaria de atribuir essa responsabilidade sobre o avanço à minha gestão. Eu prefiro a simplicidade e a modéstia. Deve ser por isso que as datas não batem. [...] Imagino que tu entendas. Mas como autora do artigo és livre para melhor explanar a respeito. (BRIGANTE, 2017)

Com a coordenação nacional, houve uma união das cidades que celebravam o DOP sem qualquer filiação ao PPP. As pessoas que coordenavam os eventos foram sendo convidadas por Lugus para se tornar oficialmente o coordenador local da sua cidade, sendo devidamente 
Religare, ISSN: 19826605, v.15, n.2, dezembro de 2018, p.652-669.

credenciada e filiada ao projeto. Esse processo envolve, além do cadastro do coordenador, o comprometimento em enviar relatórios mensais informando como anda os preparativos para o evento e, claro, um relatório final, contando como foi o Dia do Orgulho Pagão.

As cidades que realizaram o DOP em 2013 foram: Recife, Fortaleza, Rio de Janeiro, São Paulo, Botucatu, Porto Alegre, Curitiba e Palmas. Houve, durante o ano, várias reuniões via Skype dos coordenadores locais com o coordenador nacional, para compartilharem os preparativos dos eventos, as dificuldades e as ideias. $\mathrm{O}$ ano citado foi o único em que quase todas as cidades realizaram o evento no mesmo dia, 20 de outubro, apenas São Paulo não conseguiu. Foi escolhido também um tema para representar o ano, sendo ele: "Brasil de todos os deuses".

A organização e o clima de união e sucesso dos eventos de 2013 foram convidativos para a aderença de outras cidades para 2014. O processo foi o mesmo, e as novas cidades foram: Belo Horizonte, Brasília, Foz do Iguaçu, Manaus, e Santana do Livramento. Foi o ano com a maior quantidade de cidades realizando o evento, sendo no total 13. Também foi escolhido um tema, sendo ele: "Nós fazemos o mundo".

Em 2015, as cidades continuaram a realizar o evento, entrando para o projeto, Barra de São João, no Rio de Janeiro, e o tema escolhido foi "Muitas tribos, uma só nação". No entanto, conflitos que ocorreram durante o ano citado repercutiram na saída do coordenador nacional e, consequentemente, de várias cidades. Sobre o ocorrido, Lugus conta:

Retirei-me do Projeto por motivos bastante críticos e perturbadores oriundos da própria comunidade pagã brasileira, em especial, suas lideranças desesperadas em causar tumultos onde não poderiam exercer aquilo que conhecem como seu "poder de influência". O trabalho já não era nada prazeroso e sim, infelizmente, somente pesaroso. Apesar da insistência da Direção Mundial para nossa permanência no Projeto, não havia mais o que ser feito, pois se tratava de uma decisão que eu, como indivíduo, já havia 
Religare, ISSN: 19826605, v.15, n.2, dezembro de 2018, p.652-669.

tomado, e no seguimento, muitos outros coordenadores locais acabaram aderindo à auto exoneração de suas funções. Em 2015, as Coordenações Locais de Porto Alegre-RS, Santana do Livramento-RS, Curitiba-PR, Brasília-DF, Palmas-TO, Barra de São João-RJ e Botucatu-SP deixaram de existir pelos mesmos motivos acima expostos e a Coordenação Nacional para o Brasil foi dissolvida, ficando os eventos do país sob a Coordenação Geral que atua sobre toda a América Latina. (BRIGANTE, 2016)

O DOP 2016 no Brasil só foi realizado em quatro cidades, e de forma autônoma, sem reuniões, sem trocas de ideias, mas ainda com filiação com o PPP, apesar de um distanciamento deste. Em São Paulo e Fortaleza, cada qual escolheu um tema, sendo eles respectivamente "Coexistência e diálogo interreligioso" e “O religare paganus." E no Recife e em Manaus, não houve um tema específico.

Para tratarmos dos obstáculos e frutos e do diálogo inter-religioso nos DOPs, escolhemos 05 cidades, de 04 regiões do Brasil, pretendendo alcançar um panorama do evento no Brasil. Com a análise de conteúdo, procuramos investigar a presença ou a ausência de uma ou de várias características do texto. Depois de uma primeira leitura das entrevistas, codificamos trechos dela em forma de tabela, e apresentamos os resultados a seguir.

\section{Obstáculos e frutos}

Comecemos com São Paulo, uma das mais antigas cidades a celebrar o DOP, e a mais antiga que celebra initerruptamente. Nesses 15 anos do evento, houve apenas duas mudanças de coordenação. Começou sob a liderança de Claudiney Prieto, que durou 10 anos. Em 2012, o casal Tyrfang Hollydragon, e Carol Luanin tornam-se os coordenadores. Em entrevista, perguntamos a Tyrfan: Quais obstáculos e frutos que vocês tiveram? Ele disse que

Os obstáculos foram poucos, mas chatos, como por exemplo, os locais para realizar o evento, sempre tendo que justificar até o injustificável. No primeiro ano, mesmo com ofício do 
Religare, ISSN: 19826605, v.15, n.2, dezembro de 2018, p.652-669.

parque onde fizemos, anteciparam em 01 hora o fim do evento sem nos consultar. No segundo ano foi ótimo, mas a escola pública não quis uma segunda vez. [No terceiro ano, foi em uma escola particular grande ${ }^{2}$ ] Dois anos seguidos no mesmo local tranquilamente, mas a olimpíada nos roubou esse ano [2016] o local, e tivemos que penar mais uma vez para realizar. Por sorte fechamos na câmara dos vereadores, o que tornou o evento algo politico. Frutos, a completa participação do público que comprou a ideia de um evento mutante, que sempre busca novos formatos. O fato importante de ser o primeiro evento neopagão realizado em uma assembleia municipal em São Paulo, haja visto a constante realização de cultos cristãos no local. Ter podido contribuir com valores a causa da ong rancho dos gnomos e o público que ajudou muito na arrecadação de alimentos para pets. E a visibilidade dada ao movimento do orgulho pagão. (HOLLYDRAGON,2016)

O DOP em Manaus começou em 2014, portanto, há 03 edições, visto que, como já foi dito, foi uma das 04 cidades que continuaram com a celebração em 2016. Seu coordenador local em todos os eventos foi Mario Kassio. Em entrevista, ele explica que:

O obstáculo maior é o de encontrar pessoas fora do meu antigo Coven ${ }^{3}$ para palestrar e dividir experiências. Fora que a cena pagã aqui é meio tímida e o público acaba ficando em torno de 20 a 30 pessoas. O ponto positivo é que mesmo indo apenas de duas a três pessoas novas por evento, essas acabam criando vínculos com os participantes, o que as motiva a continuar a Jornada. (KASSIO, 2016)

Fortaleza teve dois coordenadores, e só conseguimos contato com o atual, Álvaro Castro, que realiza o evento desde 2013, tendo permanecido, como foi dito, até o momento. Álvaro não soube informar quando começou exatamente o DOP, apenas que já existia há alguns anos o evento em Fortaleza. Sobre os obstáculos enfrentados, o coordenador explica que:

2Acréscimo meu, para esclarecer a fala do entrevistado, que foi questionado sobre a escola que não recebeu mais o evento, por conta do aumento dos eventos esportivos, devido às olimpíadas. 3Grupo de prática religiosa wiccana. 
Religare, ISSN: 19826605, v.15, n.2, dezembro de 2018, p.652-669.

A postura do antigo coordenador já era um obstáculo. Pois ele tinha e ainda tem desavenças com muitas pessoas mais antigas da comunidade e algumas pessoas não iam ao evento por causa dele e com um tempo ele passou a não chamar algumas pessoas por não gostar delas. [...] outro obstáculo, além das desavenças, é o preconceito religioso. Alguns lugares não aceitam que façamos o DOP por ser um evento pagão. (CASTRO, 2016)

Como citado acima, Porto Alegre é a terceira cidade a sediar o DOP, e a primeira com o reconhecimento e filiação plena ao projeto. O evento ocorreu ininterruptamente de 2004 a 2015, sob a coordenação de LugusDagda Brigante e filiado ao PPP. Lugus conta que a primeira edição não teve apoio de nenhuma instituição. Mas que no ano seguinte, surge o apoio de algumas entidades, em virtude do sucesso do primeiro ano. Em entrevista, o coordenador nos conta que houve

Muitos obstáculos e pouquíssimos frutos. Contudo os obstáculos jamais vieram da sociedade como um todo, mas tão somente da própria comunidade pagã local, regional e nacional. Diversos grandes nomes do Paganismo Brasileiro, por motivos que desconheço, tentaram sabotar as atividades dos eventos em nossa cidade, mas jamais alcançaram seus objetivos. Contudo, mesmo não tendo conseguido alcançar tais objetivos, tais situações geraram tensão, mal estar e muito stress para a Coordenação Local de Porto Alegre e Sua Equipe, uma vez que o trabalho era feito com muita dedicação, esforço e carinho e o retorno recebido por parte dos líderes da comunidade pagã era somente o prejuízo, a maledicência e as tentativas de liquidação total das atividades. Foi muito desgaste físico, mágico e mental por parte da Coordenação Local. Em se tratando dos frutos, se pode mencionar as pessoas que encontraram seus caminhos espirituais nesses eventos e que também obtiveram espaço para abrirem seus contatos com outros praticantes de sendas pagãs. Aproximadamente $75 \%$ dos grupos pagãos (covens e afins) da região, surgiram a partir da reunião de pessoas que se conheciam nos eventos. Não se pode deixar de mencionar que como frutos, também foram as atividades prósolidariedade, tais como arrecadação de alimentos, produtos de higiene, roupas, todos esses devidamente entregues às instituições especializadas em cuidado com crianças carentes 
Religare, ISSN: 19826605, v.15, n.2, dezembro de 2018, p.652-669.

e idosos abandonados. Ir até os locais, distribuir as arrecadações e passar o dia com as pessoas que viviam naqueles locais era algo muito gratificante. (BRIGANTE, 2016)

A quinta cidade que abordaremos é de responsabilidade minha. Eu sou a coordenadora local do Recife. Iniciei o DOP em 2012, sem qualquer vínculo oficial ou contato com outras cidades. Após a realização do evento, fui contatada pela então estabelecida coordenação nacional. A adesão ao PPP contribuiu muito para o amadurecimento do evento no ano seguinte, e para o caráter formal e de responsabilidade social.

Os obstáculos sempre foram relacionados ao local para o evento, e a dificuldade de conseguir patrocínio para ter qualidade, estrutura e beleza no evento. Segue um depoimento cedido por mim sobre o evento a uma revista online chamada "Sombra da Lua", criada por estudantes de jornalismo como TCC. ${ }^{4}$ A entrevista foi realizada por documento word, mas via facebook, em 2015.

No primeiro ano, em 2012, foi independente, foi bem simples, compareceram por volta de 30 pessoas, e foi maravilhoso, saímos com aquele sentimento de união do movimento. Foi interessante, pois, apareceram pessoas que nunca tinham ido para os encontros usuais. Em 2013, o projeto no Brasil voltou a se organizar, e foi eleito um coordenador para o Brasil, e o DOP do Recife, passou a responder ao coordenador do Brasil, que responde ao coordenador nos EUA, e eu fui eleita oficialmente a coordenadora do Recife. O evento de 2013, já foi maior, e compareceram 100 pessoas, os dois primeiros foram na Praça da República. Nesse também apareceram pessoas novas, além dos curiosos que pararam para ver. $\mathrm{O}$ terceiro DOP, planejei para ser maior ainda, então transferi o local para o Parque da Jaqueira, e o evento foi o dia todo, das $09 \mathrm{~h}$ as $18 \mathrm{~h}$. Compareceram 150 pessoas, tivemos de novidade em relação aos outros anos, shows musicais, e comida vegana gratuita, patrocinada pelo Vegfund. Esse ano, 2015, teve o mesmo formato do anterior, e compareceu o mesmo

${ }^{4} \mathrm{O}$ site se chamava www.sombradalua.com.br, e foi desativado após a conclusão do TCC. Sua proposta era ser um canal "para dialogar com a comunidade neopagã sobre eventos locais, curiosidades, lançamento de livros e trajetórias de vida." 
Religare, ISSN: 19826605, v.15, n.2, dezembro de 2018, p.652-669.

quantitativo de 2014. Também apareceram pessoas novas e curiosos que passeavam pelo parque. (AFRODITE, 2015)

No segundo DOP, comprei uma tenda, mandei fazer cartazes, adesivos e paguei o uso do solo do parque. No terceiro e quarto, além do citado, aluguei cadeiras e o som, para os instrumentos e microfone da palestra. Solicitei e recebi contribuições de alguns grupos da cidade, mas a maioria do dinheiro sempre foi do meu bolso. Se caso conseguíssemos mais dinheiro, poderia ser um grande evento. A dificuldade de ocorrer isso, provém de outro obstáculo, que percebi durante o processo de solicitação do uso do solo: a desorganização do órgão público responsável pelos parques e o preconceito com o nome pagão. No ano de 2016, apesar do habitual costume de solicitar o espaço com antecedência, só fui informada com três dias anteriores ao evento, que não poderia utilizar som. E, quando fui negociar a permanência do evento sem o som, presenciei o deboche e descaso com o evento. Considero, inclusive, que fui vítima de intolerância religiosa. No final, consegui, mas com muita luta e insistência.

Os frutos são imensos, e é o que me dá iniciativa, força e coragem para promover o evento. Para relatar esses ganhos, irei citar uma resposta que dei à mesma entrevista aludida acima. Foi-me perguntado: qual a conquista mais notável desse projeto desde sua primeira edição?

A visibilidade que foi ganhando, e assim um maior esclarecimento sobre o paganismo, e o fortalecimento do orgulho pagão, para que as pessoas que professam a fé pagã não se sintam sozinhos, ou inferiorizados. E a construção de um momento anual celebrativo, que une com música, dança e palavras, em um espaço público, uma comunidade que é desconhecida e sigilosa em suas práticas. (AFRODITE, 2015)

\section{Diálogo inter-religioso}

O diálogo diz respeito a uma reciprocidade fundamental que se instaura entre dois polos de relação: o eu e os outros. Pressupõe sempre uma semelhança e uma diferença, uma identidade e uma alteridade. O diálogo se instaura quando 
Religare, ISSN: 19826605, v.15, n.2, dezembro de 2018, p.652-669.

ocorre uma atitude de abertura e escuta do outro, do diferente; quando se reconhece o outro como sujeito portador de uma liberdade e dignidade fundamentais. (TEIXEIRA, 2003, p. 25)

O Dia do orgulho Pagão é uma oportunidade das pessoas não Pagãs vivenciarem o diálogo inter-religioso com o Paganismo, visto que a comunidade Neopagã é semiaberta. Já o DOP é completamente aberto, gratuito e a intenção é o diálogo com a sociedade. Inclusive há uma regra nas normas do evento, que, caso haja conflitos que prejudiquem o foco do evento, que é o diálogo, aquele não poderá ser realizado. Por exemplo, um dos DOPs de Brasília chegou a ser cancelado devido a conflitos internos entre grupos diferentes, inviabilizando um evento dialogal.

No entanto, o alcance dos objetivos do evento vai variar nas diferentes cidades, talvez caracterizando o movimento da comunidade Pagã local.

Em São Paulo, Tyrfan nos contou que

O diálogo entre as religiões se estreitou no campo do paganismo, os budistas se aproximaram e o candomblé que não se considera pagão vem se aproximando. A umbanda mesmo sendo cristã tem participado, e isso é bom. O DOP aqui serve como um Elísio sem tretas convencionais. (HOLLYDRAGON,2016)

A capital paulista tem sido exemplar, o diálogo está presente internamente na comunidade e externamente na sociedade. Em 2016, o alcance da realização do evento na câmara dos vereadores, segundo Tyrfan, foi politicamente muito positivo, causou certo alvoroço, mas foi ótimo. $\mathrm{O}$ público foi de 400 pessoas incluindo palestrantes convocados e a equipe. Também tiveram mais de 396 quilos de ração arrecadados, demonstrando o engajamento dos participantes na ideologia do evento.

Em Manaus, apesar de haver um quantitativo pequeno de participantes, de acordo com o coordenador Mario, as experiências têm sido positivas. Ele conta que 
Religare, ISSN: 19826605, v.15, n.2, dezembro de 2018, p.652-669.

Com relação à contribuição para o diálogo religioso, acredito que isso já é a base dele. Os eventos sempre tentam incluir palestras e palestrantes de diversas sendas, como são abertos ao público em geral acabam somando em informação para os que não são pagãos. (CASTRO,2016)

Quando questionado se pessoas não Pagãs costumam ir ao evento, Mario disse que os que vão são normalmente acompanhantes, como namorados e amigos.

Já Fortaleza enfrenta dificuldades internas em relação ao diálogo. De acordo com o atual coordenador,

Sobre a contribuição para o dialogo religioso, é mínimo, falando em termos de Fortaleza. Quando assumi a coordenação em 2013eu busquei variar e dar voz e visibilidade no meio pagão local, vertentes até mesmo não pagãs, mas que se propunham ao diálogo aberto e irmanoso conosco. Antes era apenas um evento wiccano. (CASTRO,2016)

Porto alegre, como já foi citado acima, também teve problemas internos. No entanto, em relação ao diálogo inter-religioso, o coordenador diz que o evento proporcionou "mostrar que pagãos são pessoas normais e religiosas como àquelas de quaisquer outras denominações".

No Recife, internamente, sempre tive apoio moral da comunidade. Externamente, posso fazer a avaliação investigando o caderno de presença do evento, no qual, desde o primeiro ano solicitei nome, idade e religião do participante. Apesar de muitas pessoas não responderem a qual religião pertencem, averiguei que elas são geralmente os que não são Pagãos, seja de outra religião, ou indeciso. Desde o primeiro ano, com apenas $30^{5}$ pessoas, não Pagãos vão para o evento, e sempre houve muito respeito e interação. Transeuntes dos parques se aproximam e acabam ficando observando e até interagindo. Desde o terceiro evento, utilizo uma faixa bem grande com o

5 O segundo ano deu 67 pessoas, o terceiro 103, o quarto 102, e o quinto 85. Esses valores contradizem minha citação mais acima dada à revista. Acredito que, na época, não verifiquei o caderno de assinaturas, e arredondei bem para cima, pois muitas pessoas não assinam. 
Religare, ISSN: 19826605, v.15, n.2, dezembro de 2018, p.652-669.

nome Orgulho Pagão. A intenção é mostrar para a sociedade quem somos, e assim podermos dialogar e eliminar o preconceito.

\section{Conclusão}

Não existe um poder central no Paganismo Contemporâneo, nem é aceitável tal função por seus adeptos, mesmo entre os que desempenham papéis de liderança. Não obstante, tal negação de poder a uma instituição ou governante representa o empoderamento de todos os praticantes, pois os Pagãos também enxergam o poder como positivo e produtivo. Observamos, dessa forma, o poder na perspectiva de Michael Foucault (2012), ou seja, como uma prática social, um micropoder, que se encontra nos gestos, atitudes, comportamentos, hábitos, discursos. A não aceitação de um poder central não significa a falta de poder, mas a fragmentação consciente dele.

Quando, em 2013, é criada a coordenação nacional, e os eventos começaram a expandir-se no território brasileiro, podemos observar a criação de micropoderes legitimados por um poder maior, mas não macro. Com o fim da coordenação nacional, e o declínio das atividades de vários DOPs, conjecturamos que os coordenadores locais, sem apoio de um núcleo, não se sentiram mais legitimados a continuarem o projeto. Pois o tolhimento realizado pelos Pagãos a pretensas representações causa as citadas desavenças entre eles próprios. E tal declínio ocorre por conta de táticas e estratégias, para citar Michel de Certeau (2012), por parte de líderes da comunidade. Aqui, questionamos a pretensa ausência de monopólio que não se configura na prática, mediante as constantes denúncias de tentativas de homogeneização e promoção do ego, que, curiosamente, originam-se de todos os lados. Estamos realizando uma investigação sobre tal questão em nossa pesquisa de doutorado. 
Religare, ISSN: 19826605, v.15, n.2, dezembro de 2018, p.652-669.

Assim, consideramos que brigas entre praticantes em torno das relações de poder são um dos obstáculos para o sucesso do evento, sendo mais agravante do que o obstáculo relacionado ao local de realização, visto que não foi dito que algum DOP deixou de ser realizado por falta de local. Tal consideração serve como exemplo para futuras análises sobre as relações de poder no Paganismo contemporâneo no Brasil, assim como servem de referência apara análises concernentes ao papel das instituições na rede de poderes que impera em nossa sociedade.

Apesar das dificuldades apontadas, os frutos foram muito realçados nas falas dos entrevistados. Conseguir esclarecer e dar visibilidade ao Paganismo é uma das grandes conquistas do evento. Esta exposição da religião ao público, no entanto, mesmo que com fins positivos, é uma das causas das discórdias na comunidade. Se todo saber tem sua gênese em relações de poder, o controle de uma coordenadoria de um evento de sucesso pode legitimar o discurso de certos indivíduos, em detrimento de outros. E tal saber assegura o exercício de um poder. Talvez, por esta razão, um evento com intuitos benéficos para a comunidade religiosa estudada, tenha declinado.

Outro grande ganho produzido pelos eventos foi a possibilidade de conhecer pessoas que professam a mesma fé, e assim criar vínculos, dando uma estrutura de plausibilidade, a qual Peter Berger (2013) considera essencial para a religião. Sobre o caráter solidário, apenas os DOPs de São Paulo e Porto Alegre, destacaram tal atitude, conseguindo arrecadar boas quantidades de doações, sendo frutífera a ação.

Foi exaltado o alcance do diálogo inter-religioso no evento, conseguindo levar para o DOP pessoas não Neopagãs, de forma satisfatória. Alcançou assim, uma imagem positiva do Paganismo para a sociedade. Novamente, tal ganho pode explicar o conflito nas relações de poder, e na produção de saberes. Mas a resistência também se encontra, de forma passiva, 
Religare, ISSN: 19826605, v.15, n.2, dezembro de 2018, p.652-669.

no medo de alguns em se expor e sofrer preconceito e discriminação da sociedade.

Consideramos que, frente à forma a qual o Neopaganismo é organizado, não sendo afeito a líderes e instituições, o alcance, obstáculos, frutos, e continuação do evento dão sinais de algumas das características dessa espiritualidade no Brasil, o conflito entre anarquia e instituição, e as relações de poder daí produzidas. Também pudemos observar que tal comunidade religiosa é aberta ao diálogo inter-religioso e sofre preconceito.

Por fim, informamos que em 2017 e 2018, apenas as cidades de São Paulo, Recife e Manaus realizaram o evento e este segue de forma autônoma.

\section{Entrevistas}

AFRODITE, Karina Ártemis. Entrevista concedida ao revistaonline Sombra da Lua. 2015.

BRIGANTE, LugusDagda. Entrevista concedida a Karina Oliveira Bezerra. Facebook, 17 nov.2016, e 22 jan. 2017.

HOLLYDRAGON, Tyrfan. Entrevista concedida a Karina Oliveira Bezerra. Facebook, 17 nov.2016.

KÁSSIO, Mario. Entrevista concedida a Karina Oliveira Bezerra. Facebook, 17 nov.2016.

CASTRO, Álvaro. Entrevista concedida a Karina Oliveira Bezerra.Facebook, 17 nov.2016, e 20 jan. 2017.

\section{Referências}

BARDIN, L. Análise de Conteúdo. Lisboa: Edições 70, 2009.

BERGER, Peter. O dossel sagrado: elementos para uma teoria sociológica da religião.São Paulo: Paulos, 2013.

BOGDAN, R.; BIKLEN, S. Investigação Qualitativa em Educação: Uma Introdução à Teoria e aos Métodos. Porto: Porto Editora, 2010.

CERTEAU, Michel de. A invenção do cotidiano: 1. artes de fazer. Petrópolis, RJ: Vozes, 2012.

CLIFTON, Chas. Her hidden children: the rise of Wicca and paganismo in America. Oxford: Altamira Press, 2006. 
Religare, ISSN: 19826605, v.15, n.2, dezembro de 2018, p.652-669.

CAMBRIDGE ACADEMIC CONTENT DICTIONARY. Pagan. Disponível em: $<$ https://dictionary.cambridge.org/dictionary/english/pagan\#dataset-cacd $>$ Acesso em 26 nov.2018.

COIMBRA, C.M. B. Os Caminhos de Lapassade e da Análise Institucional: uma Empresa Possível. Revista do Departamento de Psicologia da UFF, vol7, $\mathrm{n}^{\mathbf{0}}$ 1, 1995, pp. 52-80.

FOUCAULT, Michel. Microfísica do poder. São Paulo: Graal, 2012.

FOX, Robin Lane.Pagans and Christians. New York: Knopf, 1987.

MERHY, Emerson Elias. O conhecer militante do sujeito implicado: o desafio em reconhecê- lo como saber válido.2007. Disponível em: <http://www.uff.br/saudecoletiva/professores/merhy/capitulos-02.pdf> Acesso em 02 dez.2016.

ROCHA, Maria Lopes da.Pesquisa-Intervenção e a Produção de Novas Análises. Psicologia ciência e profissão, 23 (4), 2003, 64-73. Disponível em: <http://www.scielo.br/pdf/pcp/v23n4/v23n4a10.pdf.>Acesso em 05 dez.2016. TEIXEIRA, Faustino. $O$ diálogo inter-religioso na perspectiva do terceiro milênio.Horizonte, v. 2, n. 3, Belo Horizonte, 2º sem. 2003, p. 19-38. Disponível em: http://periodicos.pucminas.br/index.php/horizonte/article/view/596/623 Acesso em 10 dez.2016.

STRMISKA, Michael (Ed.) Modern paganism in world cultures: comparative perspectives. Santa Barbara: Abc Clio, 2005.

Recebido em 11-10-2018.

Aprovado em 20-01-2019. 